\title{
Towards Creating Innovation Hub in IT- Strategy for Entrepreneurship Education at Ivan Franko National University of Lviv
}

\author{
Ihor Katernyak \\ dept. of Electronics and Computer Technology \\ at Ivan Franko National University of Lviv; \\ Ukrainian Distance Learning System, Lviv, Ukraine \\ e-mail: ikaternyak@udl.org.ua
}

\begin{abstract}
Our strategy suggests developing Entrepreneurship Education (EE) together with ecosystem for startups in the region. This requires:

shared understanding of the need for EE among the key stakeholders and encouraged collaboration on establishing an Innovation Hub as IT Startup Accelerator; find and activate champions and establish implementation mechanisms to carry out strategies and policies through a set of coherent programmes;

formulate and pilot entrepreneurship course with involvement of business experience, interactive teaching methods;

expand via more advanced courses and help business angels to meet with talented students and graduates.

IT Startup Accelerator "Innovation Hub" is to be created at the institutional level with the mission to provide support for idea development into a business concept, to invite business angels and venture capitalists for IT startups.
\end{abstract}

Index Terms - entrepreneurship education, startup, innovation hub, strategy

\section{CURRENT STATUS OF ENTREPRENEURSHIP EDUCATION}

Education and research at universities in Ukraine are structured around traditional subjects with a strong focus on natural science and basic engineering, where Ukraine has reached a high level in an international comparison. A shift from the culture of research that "can be applied" to "should be applied" requires the development of entrepreneurial mindset in the academic community. Research is still not so often closely linked to cooperation with entrepreneurs, private investors and companies. A challenge is, besides entrepreneurial thinking, to open up the universities to the surrounding society and develop entrepreneurship eco-system. Benefits of entrepreneurship education are measured not only by the number of newly created ventures and jobs but also by the entrepreneurial capacity among students, which is the basis for national well-being and prosperity, competitiveness of the region.
We conducted a survey at Ivan Franko National University of Lviv (IFU) regarding EE at the University on the base of the European best practice [1]. The survey aimed to capture the students' perspectives, and 220 students were involved in the survey: they filled in the questionnaire and were interviewed in order to assess their entrepreneurial intent, creativity and attitudes as well as the entrepreneurship perceived feasibility, perceived desirability and propensity to act, among others.

The study of main teaching methods employed (where students in IT department rated the frequency of the given methods: from never - to often), gave the following findings presented in the Figure 1 below.

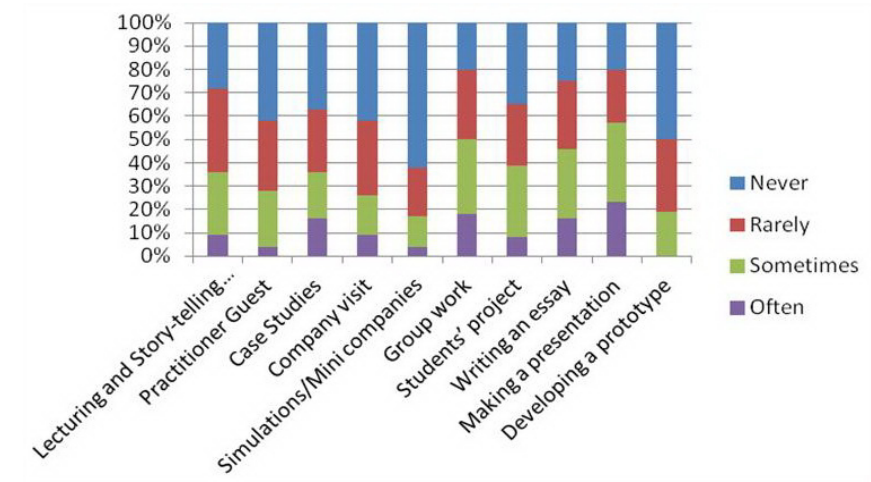

Fig. 1. Teaching methods and approaches used in classes at IFU, Ukraine

Thus, the results show that the dominant methods were students' group work, presentations, and lectures, while company visits, simulations/mini companies and developing a prototype were hardly ever used in classes at the University.

The analysed results show that the dominant methods include students' group work, presentations, and lectures, while practitioner guest lectures, company visits, simulations/mini companies and developing a prototype are hardly ever used in classes at IFU.

In terms of support, which the IT students would like to get from the University for their idea development in business, 
they mentioned internship in a company (78\%), education $(62 \%)$, and business consulting (47\%). Most interviewed students would like to have entrepreneurship course in their university curriculum (either mandatory or optional).

The respondents were then asked to identify their inner motivations, for wanting to start their own business in the future. In order to identify the range of motivating factors at interplay, respondents could freely identify as many motivational factors as applied.

For $59.6 \%$ surveyed students, the desire to achieve success and realize oneself prevails or is second most significant motive; while desire to obtain wealth takes one of the last places in the students' motivation hierarchy, as it is presented in Table 3 below.

TABLE 1. INNER MOTIVATION OF STUDENTS' ENTREPRENEURIAL INTEREST

\begin{tabular}{|l|l|}
\hline Be my own boss & 44,2 \\
\hline Independence from employer & 38,5 \\
\hline To obtain wealth & 10,6 \\
\hline Desire to achieve success and realize oneself & $\mathbf{5 9 , 6}$ \\
\hline $\begin{array}{l}\text { Passion with own idea and willingness to } \\
\text { implement it }\end{array}$ & 20,2 \\
\hline Identification of a new business opportunity & 8,7 \\
\hline Desire to innovate technologically & 29,8 \\
\hline To contribute to job creation & 16,3 \\
\hline Flexibility of working hours & 27,9 \\
\hline
\end{tabular}

The study also found that, on average, $66 \%$ of all surveyed students were interested in developing their idea while studying at the University (through the university infrastructure). These students also demonstrated their interest in the Program "Innovation and Entrepreneurship and IT area".

Despite that, there was a reported lack of student who could actually start-up within the university. This is due to the lack of existing entrepreneurial support entities and policies; lack of coordination of complementary entrepreneurship and in-company internship support activities; and lack of education and training for and about entrepreneurship. The ability to develop a business plan, risk assessment and opportunity identification were considered by Ukrainian students to be one of the most important skills and knowledge acquired within entrepreneurship education. In contrast, for students in Swedish university the top priority skills and knowledge include selling an idea and finding customers as well as communication and presentation skills.

Growing evidence suggests that successful entrepreneurs depend more on their soft skills and personal development as well as on their ability to be able to adjust flexibly to the marketplace and less on formal business planning. These findings suggest that, in general, the universities should promote entrepreneurship as a career option and provide entrepreneurship experiences to IT students, if the goal of creating the entrepreneurial graduate is to be achieved.

However, entrepreneurship education programs for IT-area students are also confronted with some specific challenges. Despite numerous initiatives focused on forming crossdisciplinary programs for promoting leadership, and launching new curricula that respond to the labor market needs, business and entrepreneurial mind-set has not been developed enough in academic communities. So, the change in the academic culture is the common challenge, which includes the introduction of entrepreneurial thinking and acting as alternatives to traditional teaching approaches and opening up the universities to the surrounding society and industrial ecosystem.

The "Innovation and Entrepreneurship in IT area" course for students of the Departments of Electronics and Computer Technology, Applied Maths, was supported by Stockholm University (Department of Computer and System Sciences), organized by UDL and SoftServe company in September December from 2012 to 2017. The Course Syllabus included the following topics: Creativity and Innovation; Requirements for starting a new business: NABC model [2]; The Lean Startup [3, 4]; Bootstrap finance and Business angel involvement; Marketing and Sales in practice; Venture capital and Crowdfunding.

The programme also included pitch training, practicing pitch presentations of team projects, guest speakers from startups, consulting and investment companies. Upon successful completion of the course and pitch presentations of their business idea or startup project, students had an opportunity to be interviewed by successful entrepreneurs from Ukraine and Sweden and be invited to have internship in one of the IT cluster companies in Lviv or Stockholm. Such course provided a unique experience for students, it increased their motivation to implement the ideas and to startup. Also, pitch and general presentation skills are essential for students.

It was noted that young people in Ukraine have no confidence in their own abilities to start a business and to find bootstrap finance, they are often afraid of taking risks and making the first step, which is the main thing for entrepreneurship. Key lesson taken by the students can be formulated as follows: "There is nothing impossible" and "Doing business is simple". So it is essential to make clear that entrepreneurship is a change, because through entrepreneurship innovations come into the society, and entrepreneurship assists in creating jobs.

II.STRATEGY FOR ENTREPRENEURSHIP EDUCATION AT IVAN FRANKO NATIONAL UNIVERSITY IN LVIV, UKRAINE “TOWARDS CREATING INNOVATION HUB IN IT"

Below follows a proposed step-by-step strategy to establish EE at IFU and creation of the Innovation Hub as an 
eco-system of stakeholders (e.g. business-angels, investors, experts, coaches, successful entrepreneurs).

In order to define the strategy, we have conducted the following steps:

- Identification of local and international best practice

- Conducted entrepreneurship course in close collaboration with industrial partners

- Evaluation of course

- Offered international entrepreneurship internship at innovative companies to students

- Workshop with innovation expert sharing experiences

In summary, a wide range of activities have been conducted in order to identify good examples, conduct actual entrepreneurship education, adapt experiences and knowledge to local business climate.

Step 1 Shared understanding of the need for Entrepreneurship

In order to establish entrepreneurship education, several key stakeholders should support the initiative. These stakeholders are to be continuously informed and sometimes educated in order to reach a positive decision. This step consists of drawing up a list of potential stakeholders, formulating questions for the interview to define the specific needs of the IT industry and IT-related education, and conducting a number of meetings with defined persons.

This approach allows the stakeholders to act as co-authors of the EE Strategy and take on joint responsibility for achievement of the set goals (outcomes).

Conduct a 'round table' with representatives of the stakeholders:

- encourage collaboration on entrepreneurship and entrepreneurship education across universities both in Lviv and in the region in general;

- encourage local and regional governments to work with other stakeholders in order to establish an Innovation Hub.

Post the draft Strategy on the web-sites of IFU and UDL for receiving feedback and comments from researchers and students.

UDL reviewed and analysed the stakeholders' comments and suggestions concerning the draft programme, and based on these recommendations, shall offer an updated version of the Strategy, with amendments and changes.

We completed this step in March, 2014.

\section{Step 2 Find and activate champions}

Learn from pilot initiatives, including our course on Innovation and Entrepreneurship, find active champions, and then work to scale the effective programmes.
Organize a workshop on SWOT and GAP analyses to evaluate the prospects of implementing the Entrepreneurship Education and Innovation Hub, with involvement of representatives of IT industry, various levels of the University management, faculty staff, students, graduates. During such Workshop, leaders are to be defined, and a working group (WG) to be created by representatives of the main stakeholders.

The WG is to develop a schedule of the Strategy presentations, it shall organize their conduct and thus, the final version of the Strategy will be received.

Establish implementation plan and mechanisms (public or private agencies and/or foundations) to carry out strategies and policies through a set of coherent programmes.

We are going to complete this step by May 2019 .

\section{Step 3 Formulate basic entrepreneurship course}

The Course curriculum is to be developed: a syllabus, schedule of classes, evaluation methods and tools, methodological guide for students, web-platform for eLearning will be created and e-course designed [5];. The curriculum is to be presented to local business community for review and ensuring the development of industry relevant course materials.

Facilitate and encourage private sector links with academia by involving the University faculty staff and students in business operations within IT companies.

Encourage partnerships between existing programmes and initiatives as appropriate to better leverage resources and expand impact.

Facilitate cross-disciplinary programmes in the area of EE and encourage student-led initiatives and activities to flourish.

Innovation Hub/web-portal (Generation I) for eLearning is to be created.

We aim to have completed this step by July 2019 .

\section{Step 4 Activate and engage local business community}

The Course is to be implemented in the university-industry partnership using F2F class, video-lectures, eLearning formats, and representatives of local business community are to be involved as mentors, guest speakers, offering practical cases and hosting students' internship.

Facilitate a consistent and adequate level of funding for EE programmes.

The Business Angels Network is created where angel investors can come together to collaborate, learn and explore synergies in order to help create new enterprises.

Innovation hub/ web-portal (Generation II) for Business Angels Network, on the one hand, and idea pitches and startups, on the other hand, is to be developed and promoted.

We aim to complete this step in 2020/21 academic year. 
Step 5 Expand via more courses and more advanced courses

More specialized courses are to be offered in such topics as Cloud industry, Mobile application, Database, Security, Energy saving programming, Hardware oriented programming etc.:

- $\quad$ assisting teachers at IFU in efforts to modernize the curricula, in particular, to bring more practical cases and tools into the labs and students' tasks;

- introducing modern software programming methodologies and development tools, methods and techniques used in leading IT companies worldwide.

Encourage faculty to use interactive teaching methods (case studies, games, projects, laboratories, etc.) and create a network for sharing and exchanging the practices.

Provide incentives, not only for the course development, but also for the sharing of materials throughout the University and EE programmes using eLearning techniques.

Innovation Hub/web-portal (Generation III) for meeting with talented students and graduates.

We aim to have completed this step by September 2020.

\section{Step 6 Engage in entrepreneurship research activities}

Organizing a "Research and Innovation" course and workshop 'From Idea to Marketplace' and Innovation Spring Forum for young researchers involved in:

- implementation of automated systems for data collection and management on the base of various types of interfaces;

- successful application of various methods of processing and analysing large mass of information;

- $\quad$ effective methods for identification and security;

- programming software vs. hardware for neuronetworks.

Since 2005, IFU, together with UDL, have initiated and supported an annual event - Innovation Spring, which includes: a series of workshops "From Idea to Marketplace", Idea Competition - "Idea Marathon", and final Innovation Spring Forum where students and young researchers present their innovation concepts to business and research communities. During the recent one Innovation Spring Forum - "Lviv Towards Industry 4.0 and Digital Innovation" - some successful stories by research groups were presented and pitches on IT startups aimed at solving municipal problems, presented by ten youth teams, brought in energy to the event. They were evaluated by the jury, and winners received financial incentive for the best projects.

Also, Innovation Hub/web-portal (Generation IV) for knowledge intensive services and technology-based startups is to be prepared.

We are planning to complete this step during November 2020 - May 2021.
Step 7 Build innovation institutions such as incubators / accelerators

The IT Startup Accelerator "Innovation Hub" is to be created at the institutional level with the mission to improve students' entrepreneurial mind-set and their ability to think different, to give practical tools for idea generation, to encourage diversity, to develop a high level of freedom in thinking and acting and to provide support for idea development into a business concept, to invite business angels and venture capitalists for IT startups.

Technology trends fir startups include: Cloud Computing, Big Data, AI (Artificial Intelligence) ,Bot, Blockchain, Virtual Reality, Augmented Reality [6].

Innovation Hub should be integrated with the relevant infrastructure of universities, with allocated resources, strong leadership and advocacy from top management. The Innovation Hub team invites, engages and builds the Innovation $\mathrm{Hub}$ as an eco-system of stakeholders (e.g. business-angels, investors, experts, coaches, successful entrepreneurs). The Accelerator partners conduct mentoring sessions (master classes) on business models with invited mentors/business angels, and then pitches of projects are to be made to the investment committee. It also offers legal and media support.

We aim to have completed this step by September 2022.

The implementation of the suggested steps will ensure the development of Entrepreneurship Education and eco-system for IT startups in the region.

\section{ACKNOWLEDGEMENTS}

We would like to acknowledge the following organisations for their valued contributions in developing the Strategy for Entrepreneurship Education at Ivan Franko National University of Lviv: Lviv City Council (Foreign Economic Relations and Investments Office), Ukraine; Ukrainian Distance Learning System (UDL), Ukraine; SoftServe Inc, Ukraine; Stockholm University (Department of Computer and System Sciences), Sweden; Ayond AB, Sweden

\section{REFERENSES}

[1] Entrepreneurship Education in Ireland Towards Creating the Entrepreneurial Graduate.- National Council for Graduate Entrepreneurship (NCGE). 2009. P.118

[2] Innovation - The five disciplines for creating what customers want / Stanford Research Institute, SRI Carlson \& Wilmot. - 2006.

[3] Ries E. The Lean Startup: How Today's Entrepreneurs Use Continuous Innovation to Create Radically Successful Businesses / Ries Eric. Crown Publishing, 2011. - P.103.

[4] Blank S. Why the Lean Start-Up Changes Everything / Steve Blank. Harvard business review. - May 2013.

[5] Katernyak I, Ekman S. and others eLearning: from social presence to cocreation in virtual education community. / // Interactive Technology and Smart Education. - Emerald Group Publishing Ltd, 2009. P 215-222

[6] A startup guide and toolkit for local government. A resource to support startup activities.- Lanchvic, KPMG-November 2017 